\title{
Distribution of selected gene polymorphisms of UGT1A1 in a Saudi population
}

Khalid M. Alkharfy,1,2, Amal M. Alghamdi' Khawla M. Bagulb³, Fahad I. Al-Jenoobi ${ }^{4}$, Abdullah M. Al-Mohizea ${ }^{4}$, Saleh Al-Muhsen³, Rabih Halwani ${ }^{3}$ Mohammad K. Parvez ${ }^{5}$, Mohammed S. Al-Dosari ${ }^{5}$

1Department of Clinical Pharmacy, College of Pharmacy, King Saud University, Riyadh, Saudi Arabia

2Biomarkers Research Program, College of Pharmacy, King Saud University, Riyadh, Saudi Arabia

3Department of Pediatrics, Asthma Research Chair and Prince Naif Center for Immunology Research, College of Medicine, King Saud University, Riyadh, Saudi Arabia

4Department of Pharmaceutics, College of Pharmacy, King Saud University, Riyadh, Saudi Arabia

${ }^{5}$ Department of Pharmacognosy, College of Pharmacy, King Saud University, Riyadh, Saudi Arabia

Submitted: 17 February 2012

Accepted: 16 July 2012

Arch Med Sci 2013; 9, 4: 731-738

DOI: 10.5114/aoms.2013.37012

Copyright $\odot 2013$ Termedia \& Banach

\section{Abstract}

Introduction: Glucuronidation is an important phase II pathway responsible for the metabolism of many endogenous substances and drugs to less toxic metabolites, which undergo renal excretion. The aim of the current work was to evaluate genotype and allele frequencies of certain UDP-glucuronosyltransferase 1A1 (UGT1A1) variants in an Arab population.

Material and methods: Genomic DNA was isolated from 192 healthy unrelated Saudi males of various geographic regions and genotyping of UGT1A1*6, *27, ${ }^{*} 36,{ }^{*} 28,{ }^{*} 37$, and ${ }^{*} 60$ was carried out using polymerase chain reaction (PCR) amplification followed by direct sequencing.

Results: The most common allele for (TA) repeats was the wild type (TA) 6 with a frequency of $74.3 \%$ followed by the mutant (TA)7 (i.e., UGT1A1*28) with a frequency of $25.7 \%$. The distribution of UGT1A1* 60 allele was $62.4 \%$ among subjects with the homozygous mutant genotype of $35.4 \%$, while the wild type variant represents $10.6 \%$ only. Both UGT1A1* 6 and ${ }^{*} 27$ were not detected as all screened subjects showed a homozygous wild type pattern. Similarly, UGT1A $1 * 36^{*}$ and ${ }^{*} 37$ were either not present or rarely found, respectively. In comparison to other populations, the frequency of UGT1A1* 60 and ${ }^{*} 28$ in the studied population was less than that of African Americans but higher than Asians. The geographical origin of the study subjects also implied some differences in genotype distribution of (TA) repeats and UGT1A1*60.

Conclusions: Our data indicate that Saudis harbor some important UGT1A1 mutations known to affect enzyme activity. Additional studies are warranted to assess the clinical implications of these gene polymorphisms in this ethnic group.

Key words: glucuronidation, UDP-glucuronosyltransferase 1A1, gene polymorphism, Saudi Arabians.

\section{Introduction}

Glucuronidation catalyzed by UDP-glucuronosyltransferases (UGT) is an important pathway through which endogenous and exogenous

\author{
Corresponding author: \\ Mohammed S. Al-Dosari PhD \\ Assoc. Prof. \\ College of Pharmacy \\ King Saud University \\ P.O. Box 2457 \\ Riyadh 11451, Saudi Arabia \\ Phone: +9661 4677252 \\ Fax: +9661 4677245 \\ E-mail: msdosari@yahoo.com
}


compounds are detoxified to less active counterparts [1]. The UGT1A locus in humans is on the long arm of chromosome 2 (2q37.1) and spans approximately $160 \mathrm{~kb}$. UGT1A contains at least 9 promoters and first exons that can be spliced with four common exons (exons 2-5) to produce UGT1A1-UGT1A9. The UGT2 family is divided into the $2 \mathrm{~A}$ (three genes) and $2 \mathrm{~B}$ (seven genes and five pseudogenes) subfamilies on chromosome 4 (4q13). Of the UGT1A isoforms, UGT1A1 (533aa, NM_000463.2) is primarily responsible for the glucuronidation of bilirubin in the human liver and can also conjugate phenols, anthraquinones, flavonoids, and a variety of therapeutic drugs and their metabolites (e.g., SN-38, the active metabolite of irinotecan) [2,3]. This UGT isoform is expressed in biliary tissue, colon, intestine, liver, and stomach [4].

Alterations in UGT enzyme function may ultimately affect clearance of, and therefore, systemic exposure to those compounds. Several functional polymorphisms in UGT1A1 are associated with reduced bilirubin glucuronidation activity and can cause hyperbilirubinemia (i.e., Gilbert and CriglerNajjar syndromes). A TA insertion in the UGT1A1 promoter region to produce a (TA)7TAA sequence instead of (TA)6TAA is associated with reduced UGT1A1 transcription [5]. This variant (i.e., (TA)7TAA' UGT1A1*28') is associated with reduced glucuronidation of SN-38 (an active irinotecan metabolite) and bilirubin, as well as the pathogenesis of Gilbert syndrome [6]. Another variant, UGT1A1*60, is a T-to-G substitution at nucleotide -3279 in the UGT1A1 phenobarbital-responsive enhancer module that reduces transcriptional activity [7]. In addition, two single nucleotide polymorphisms (SNPs) are described in exon 1 resulting from G-to-A substitution at 211 nucleotide (Gly71Arg; UGT1A1*6) and C-to-A at 686 nucleotide (Pro229Gln; UGT1A1*27), which are associated with reduced enzyme activity $[8,9]$.

The prevalence of certain UGT1A variants has been determined in some ethnic groups. The most common non-synonymous SNP (UGT1A1*6) that causes an amino acid alteration (a Gly71Arg switch) is found in Asian populations at frequencies of 13$23 \%$ [10]. The UGT1A1*27 genotype has a frequency of $2.8 \%$ in Taiwanese [11], while UGT1A1* $28 /{ }^{\star} 28$ exists in $2.3 \%$ of Koreans [12]. The frequency of the UGT1A $1 * 28$ homozygous genotype in an Eastern Scottish population was estimated to be $10-13 \%$, whereas the allelic frequency of UGT1A1*60 is $26.2 \%$ in Japanese [6, 13].

Apart from a few small sample size reports ( $n=42-61)$ on the frequency of TATA box polymorphism of UGT1A1 in some Middle-Eastern populations [14, 15], information of important UGT1A1 gene variations in the Arabian ethnicity is lacking. There- fore, the aim of this study is to investigate the frequencies of selected UGT1A1 variants in Saudi Arabians and therefore provide essential information on this specific ethnic group. This should also shed some light on the clinical implications of these mutations in relation to disease occurrence and therapeutic efficacy and toxicity of drugs known to be metabolized by UGT1A1.

\section{Material and methods}

\section{Human subjects}

A total of 192 apparently healthy unrelated Saudi male volunteers (20-25 years old) of various geographic regions were recruited to the study from King Saud University, Riyadh, Saudi Arabia. The study's objectives were explained and one time venous blood sample $(\sim 20 \mathrm{ml})$ was obtained in EDTA tubes from each subject after obtaining written informed consent from all participants. The ethical approval of the study was granted by the Institutional Review Board of the College of Medicine, King Saud University, Riyadh, Saudi Arabia.

\section{Genetic testing}

DNA extraction was carried out using Puregene Blood Core Kit C (Qiagen, Germantown, MD, USA) following the manufacturer's instructions and quantified using a Nanodrop 2000 Spectrophotometer (Thermo Scientific, Wilmington, DE, USA). The indicated polymorphic variants were amplified in a Veriti ${ }^{\circledR}$ 96-Well Fast Thermal Cycler (Applied Biosystems, Foster (ity (A, USA) in a total volume of $25 \mu \mathrm{l}$, containing $20 \mathrm{ng}$ DNA, $0.25 \mu \mathrm{l}$ (2.5 mM) of dNTPs (Epicentre Biotechnologies, Madison, WI, USA), $2 \mu \mathrm{l}$ (10 pM) of primers (Metabion, Martinsried, Germany) and $0.3 \mu \mathrm{l}(5 \mathrm{U} / \mu \mathrm{l})$ of HotstarTaq DNA polymerase (Qiagen, Germantown, $M D, U S A)$. For PCR, an initial denaturation step at $95^{\circ} \mathrm{C}$ for $10 \mathrm{~min}$ was followed by 35 cycles of denaturation at $94^{\circ} \mathrm{C}$ for $40 \mathrm{~s}$, annealing at the indicated temperature for $40 \mathrm{~s}$, and extension at $72^{\circ} \mathrm{C}$ for $45 \mathrm{~s}$, followed by a final extension step of $72^{\circ} \mathrm{C}$ for $10 \mathrm{~min}$. Primer sequences and their annealing temperatures are listed in Table I. The PCR amplicons were evaluated by $2 \%$ agarose gel electrophoresis and then purified using an MCEmembrane MultiScreen plate (Millipore, Billerica, MA, USA) pre-packed with G-50 superfine Sephadex (GE Healthcare, Piscataway, NJ, USA). The purified PCR amplicons were then sequenced by dye termination sequencing using BigDye Terminator Cycle Sequencing V3.1 Kit and 3730xI DNA Analyzer (Applied Biosystems, Foster City, CA, USA). DNA sequences were analyzed using the Seqman program of the DNASTAR analysis package (Lasergene, Madison, WI, USA). 
Table I. Primer sequences and annealing temperatures

\begin{tabular}{|lccc|}
\hline UGT1A1 & Forward primer & Reverse primer & Annealing temperature \\
\hline UGT1A1*6 $\left(\right.$ rs4148323) $^{*}$ CAGCAGAGGGGACATGAAAT & CAAAAACATTATGCCCGAGAC & 57 \\
\hline UGT1A1 $^{*} 27($ rs35350960) & GGCCTCTCTCCTCTCATTCA & TGGGCCTAGGGTAATCCTTC & 57.5 \\
\hline UGT1A1*36, $28,{ }^{*} 37($ rs34815109) & TGCTACCTTTGTGGACTGAC & TATCTTCCCAGCATGGGACAC & 55 \\
\hline UGT1A1*60 (rs4124874) & ACTTGGTAAGCACGCAATG & GCCTTGCTCTCAAAACTCTG & 55 \\
\hline
\end{tabular}

\section{Statistical analysis}

Frequency is expressed as percentage with 95\% confidence interval $(\mathrm{Cl})$. Haplotype frequencies were estimated by the expectation-maximization algorithm (EM algorithm) implemented in PROC Haplotype in SAS Genetics statistical software package (SAS Institute, Cary, NC, USA). The standardized measure of linkage disequilibrium (LD), termed D' and $\mathrm{R}$, was computed at pairs of polymorphic loci.

\section{Results}

Allele and genotype frequencies of UGT1A1 are given in Table II. Possible genotypes related to the presence of UGT1A1 variants were observed in the

Table II. Allele and genotype frequencies of UGT1A1 polymorphisms in the Saudi population

\begin{tabular}{|c|c|c|c|}
\hline Variant & $N$ & Frequency [\%] & $95 \% \mathrm{Cl}$ \\
\hline \multicolumn{4}{|c|}{ Genotype UGT1A1*60 (-3279 T>G) } \\
\hline UGT1A1*T/*T & 20 & 10.6 & $(6.2,14.9)$ \\
\hline UGT1A $1^{\star} \mathrm{G} /{ }^{*} \mathrm{G}$ & 67 & 35.4 & $(28.6,42.3)$ \\
\hline UGT1A1*T/*G & 102 & 54.0 & $(46.8,61.1)$ \\
\hline \multicolumn{4}{|l|}{ Allele } \\
\hline UGT1A1*T & 142 & 37.6 & $(32.7,42.4)$ \\
\hline UGT1A1*G & 236 & 62.4 & $(57.5,67.3)$ \\
\hline \multicolumn{4}{|c|}{ Genotype UGT1A1*28,*37 ((TA)6>7,8) } \\
\hline UGT1A1 * $(\mathrm{TA}) 6{ }^{*}(\mathrm{TA}) 6$ & 94 & 50.0 & $(43.1,57.4)$ \\
\hline $\mathrm{UGT}_{1 A}{ }^{\star}(\mathrm{TA}) 6{ }^{*}(\mathrm{TA}) 7$ & 90 & 47.9 & $(40.9,55.3)$ \\
\hline UGT1A1*TA7/*(TA)7 & 3 & 1.6 & $(0.7,4.1)$ \\
\hline $\operatorname{UGT1A1}^{*}(\mathrm{TA}) 8^{*} /{ }^{*}(\mathrm{TA}) 8$ & 1 & 0.5 & $(0.1,2.4)$ \\
\hline \multicolumn{4}{|l|}{ Allele } \\
\hline $\mathrm{UGT1A}^{\star}(\mathrm{TA}) 6$ & 278 & 74.3 & $(69.9,78.7)$ \\
\hline $\mathrm{UGT1A1}^{\star}(\mathrm{TA}) 7$ & 96 & 25.7 & $(21.2,30.1)$ \\
\hline UGT1A1*(TA)8 & 2 & 0.5 & $(0.2,1.6)$ \\
\hline \multicolumn{4}{|c|}{ Genotype UGT1A1*6 (211 G>A) } \\
\hline UGT1A $1^{\star} \mathrm{G} /{ }^{\star} \mathrm{G}$ & 182 & 100 & - \\
\hline UGT1A $1^{*} A /{ }^{*} A$ & 0 & 0 & - \\
\hline $\mathrm{UGT1A} 1^{*} \mathrm{G} /{ }^{*} \mathrm{~A}$ & 0 & 0 & - \\
\hline \multicolumn{4}{|l|}{ Allele } \\
\hline UGT1A1*G & 364 & 100 & - \\
\hline UGT1A1*A & 0 & 0 & - \\
\hline \multicolumn{4}{|c|}{ Genotype UGT1A1*27 (686 C>A) } \\
\hline $\mathrm{UGT} 1 \mathrm{~A} 1^{\star} \mathrm{C} /{ }^{*} \mathrm{C}$ & 181 & 100 & - \\
\hline UGT1A1 ${ }^{*} \mathrm{~A} /{ }^{*} \mathrm{~A}$ & 0 & 0 & - \\
\hline $\mathrm{UGT} 1 \mathrm{~A} 1^{*} \mathrm{C} /{ }^{*} \mathrm{~A}$ & 0 & 0 & - \\
\hline \multicolumn{4}{|l|}{ Allele } \\
\hline UGT1A1*C & 362 & 100 & - \\
\hline UGT1A1*A & 0 & 0 & - \\
\hline
\end{tabular}


A

G G

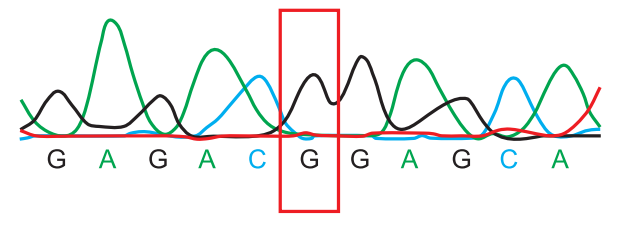

B

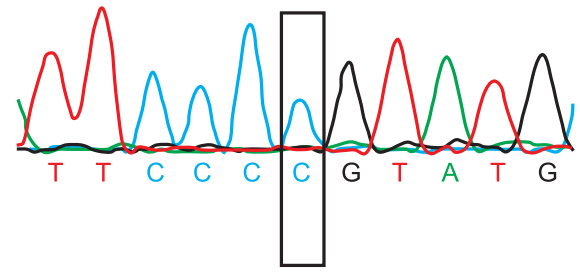

C

(TA)6

(TA)6/(TA)7

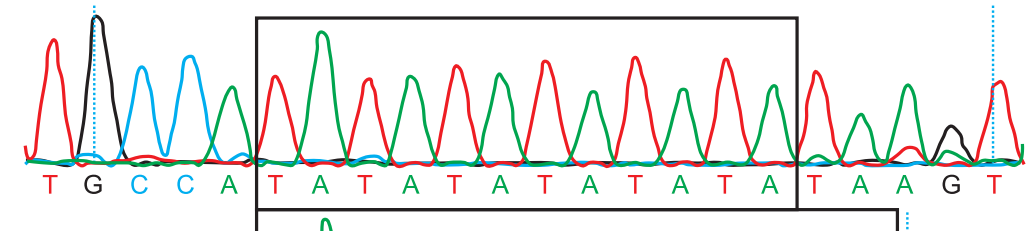

(TA)7

(TA)8
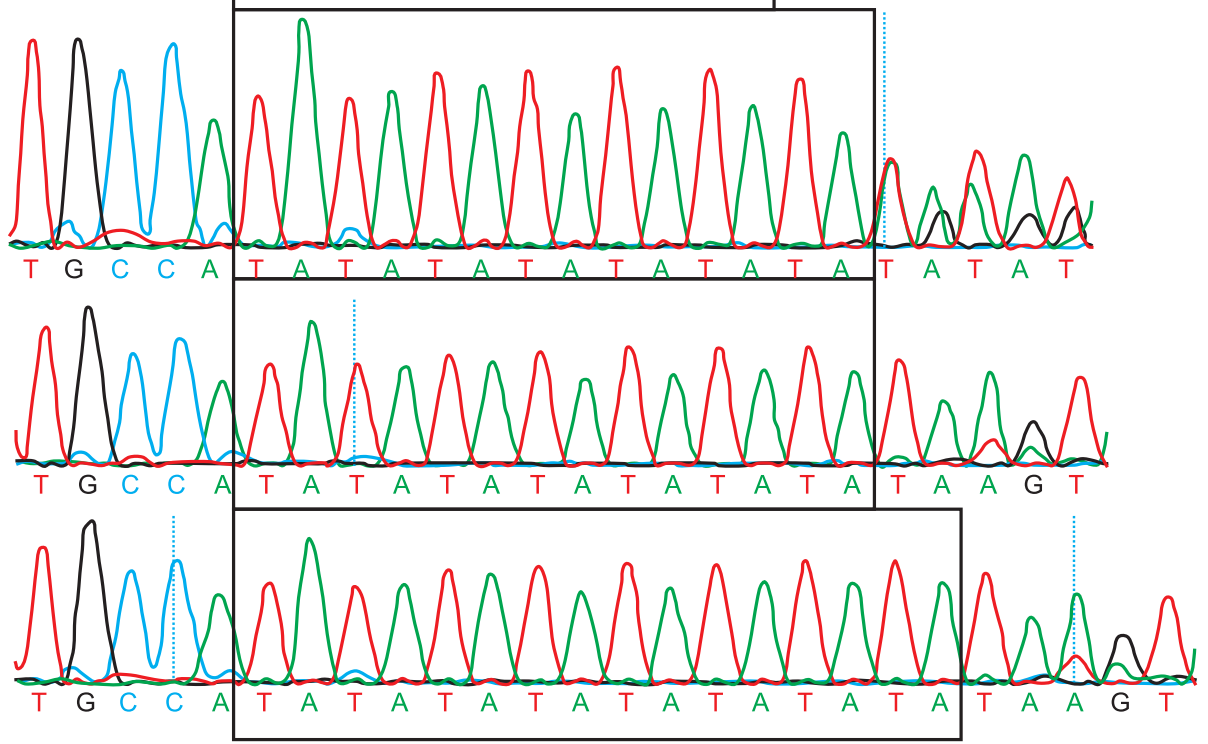

D

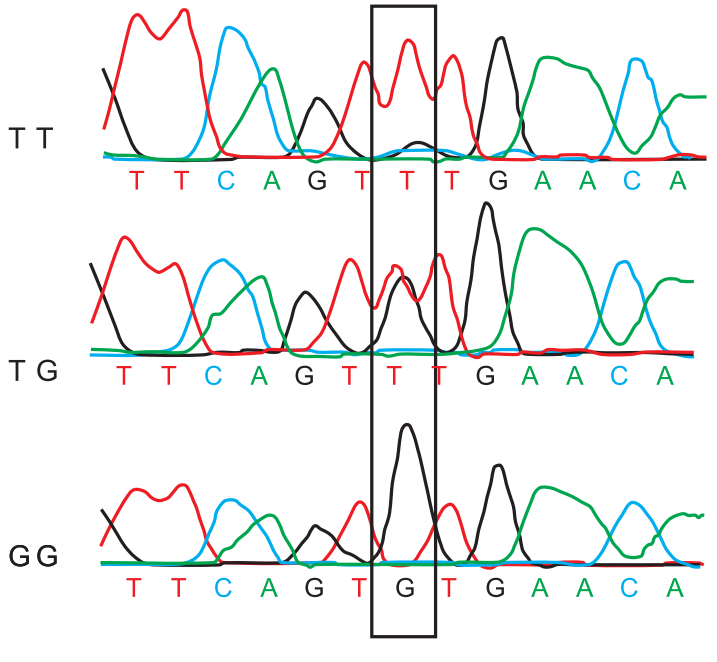

studied population. The most common allele for (TA) repeats was (TA) 6 with a frequency of $74.3 \%$ $(n=278)$ followed by the mutant (TA)7 allele (i.e., UGT1A1*28) with a frequency of $25.7 \%$. The distribution of UGT1A1* 60 allele was $62.4 \%$ among sub-
Figure 1. Sequence chromatograms showing $A-U G T 1 A 1^{*} 6($ c. $211 G>A), B-U G T 1 A 1^{*} 27($ c. $686 C>A)$, C - UGT1A1*28 (C. -53 - 52 insTA), and D - UGT1A1*60 (c.-3279T>G) allelic variants indicated by boxes 
Table III. Allele and genotype frequencies of UGT1A1 polymorphisms in Saudi subjects of various geographical origins

\begin{tabular}{|c|c|c|c|c|c|}
\hline Variable & $\begin{array}{l}\text { Central } \\
(n=80)\end{array}$ & $\begin{array}{l}\text { Southern } \\
(n=52)\end{array}$ & $\begin{array}{l}\text { Western } \\
(n=17)\end{array}$ & $\begin{array}{l}\text { Northern } \\
(n=20)\end{array}$ & $\begin{array}{l}\text { Eastern } \\
(n=32)\end{array}$ \\
\hline \multicolumn{6}{|l|}{ UGT1A1*60 (-3279 T>G) } \\
\hline $\mathrm{TT}(\mathrm{N})$ & 11 & 5 & 3 & 1 & 0 \\
\hline GT (N) & 39 & 33 & 6 & 11 & 13 \\
\hline GG (N) & 30 & 13 & 6 & 8 & 10 \\
\hline$T(N)$ & 61 & 43 & 12 & 13 & 0 \\
\hline$G(N)$ & 99 & 59 & 18 & 27 & 33 \\
\hline $\mathrm{TT}(\mathrm{N} \%$ 95\% Cl) & $13.7(6.2,21.3)$ & $9.8(1.6,17.9)$ & $20(0.24,40.2)$ & $5(1.2,14.5)$ & - \\
\hline GT (N\% 95\% Cl) & $48.7(37.8,59.7)$ & $64.7(51.6,77.8)$ & $40(15.2,64.8)$ & $55(33.2,76.8)$ & $56.5(36.3,76.8)$ \\
\hline GG (N\% 95\% Cl) & $37.6(26.8,48.1)$ & $25.5(13.5,37.3)$ & $40(15.2,64.8)$ & $40(18.5,61.5)$ & $43.5(23.2,63.7)$ \\
\hline $\mathrm{T}(\mathrm{N} \% 95 \% \mathrm{Cl})$ & $38.2(30.6,45.6)$ & $42.2(32.6,51.7)$ & $40(22.4,57.5)$ & $32.5(17.9,47.0)$ & - \\
\hline $\mathrm{G}(\mathrm{N} \% 95 \% \mathrm{Cl})$ & $61.8(64.3,69.4)$ & $57.8(48.3,67.4)$ & $60(22.4,57.5)$ & $67.5(52.9,82.0)$ & 100 \\
\hline \multicolumn{6}{|l|}{ UGT1A1*TA6,7,8 } \\
\hline UGT1A1*TA6/*TA6 (N) & 38 & 28 & 9 & 11 & 8 \\
\hline UGT1A1*TA6/*TA7 (N) & 38 & 23 & 7 & 8 & 14 \\
\hline UGT1A1*TA7/*TA7 (N) & 2 & 1 & 0 & 0 & 0 \\
\hline UGT1A1*TA8/*TA8 (N) & 0 & 0 & 1 & 0 & 0 \\
\hline UGT1A1*TA6 (N) & 114 & 79 & 25 & 30 & 30 \\
\hline UGT1A1*TA7 (N) & 42 & 25 & 7 & 8 & 14 \\
\hline UGT1A1*TA8 (N) & 0 & 0 & 2 & 0 & 0 \\
\hline $\begin{array}{l}\text { UGT1A1*TA6/*TA6 } \\
\text { (N\% 95\% CI) }\end{array}$ & $48.7(37.6,59.8)$ & $53.8(40.3,67.4)$ & $52.9(29.2,76.7)$ & $57.9(35.7,80.1)$ & $36.4(16.2,56.4)$ \\
\hline $\begin{array}{l}\text { UGT1A1 } 1^{*} \text { TA6/*TA7 } \\
\text { (N\% 95\% Cl) }\end{array}$ & $48.7(37.6,59.8)$ & $44.2(30.7,57.7)$ & $41.2(29.2,76.7)$ & $42.1(19.9,64.3)$ & $63.6(43.5,83.7)$ \\
\hline $\begin{array}{l}\text { UGT1A1TA7/*TA7 } \\
\text { (N\% 95\% CI) }\end{array}$ & $2.6(0.01,6.1)$ & $2.0(0.08,5.6)$ & - & - & - \\
\hline $\begin{array}{l}\text { UGT1A1 } 1^{*} \text { TA8 } /{ }^{*} \text { TA8 } \\
\text { (N\% 95\% CI) }\end{array}$ & - & & $5.9(2.1,17.0)$ & - & - \\
\hline $\begin{array}{l}\text { UGT1A1*TA6 } \\
\text { (N\% 95\% CI) }\end{array}$ & $73.1(66.1,80.0)$ & $75.9(67.7,84.1)$ & $73.5(58.7,88.4)$ & $78.9(65.9,91.9)$ & $68.2(54.4,81.9)$ \\
\hline $\begin{array}{l}\text { UGT1A1*TA7 } \\
\text { (N\% 95\% CI) }\end{array}$ & $26.9(19.9,33.8)$ & $24.1(15.8,32.2)$ & $20.6(7.0,34.2)$ & $21.1(8.1,34.0)$ & $31.8(18.1,45.6)$ \\
\hline UGT1A1*TA8 (N\% 95\% Cl) & - & - & $5.9(2.4,17.4)$ & - & - \\
\hline \multicolumn{6}{|l|}{ UGT1A1*6 (211 G>A) } \\
\hline GG (N) & 77 & 46 & 15 & 19 & 23 \\
\hline GG (N\% 95\% Cl) & 100 & 100 & 100 & 100 & 100 \\
\hline \multicolumn{6}{|l|}{ UGT1A1*27 (686 C>A) } \\
\hline $\mathrm{CC}(\mathrm{N})$ & 74 & 51 & 16 & 19 & 21 \\
\hline $\mathrm{CC}(\mathrm{N} \% 95 \% \mathrm{Cl})$ & 100 & 100 & 100 & 100 & 100 \\
\hline
\end{tabular}

The geographical origin of participants also revealed some differences in allele distribution. For example, all studied subjects from the Eastern region demonstrated a UGT1A1*60 mutant allele, whereas this mutation was found in about
$58-68 \%$ in other regions (Table III). Similarly, the UGT1A1*TA6/*TA6 wild genotype was found least often in Eastern Saudis ( $36 \%$ ) and highest in those of Northern descent ( $58 \%)$. Out of all the studied population, only one subject from the Western 
Table IV. UGT1A1 haplotypes in the studied subjects

\begin{tabular}{|lccc|}
\hline Haplotype & $\boldsymbol{N}$ & Frequency [\%] & $95 \% \mathrm{Cl}$ \\
\hline $\mathrm{UGT1A1}^{*} 60 \mathrm{G}+\mathrm{UGT1A1}^{*}(\mathrm{TA}) 7$ & 30 & 16.2 & $(10.9,21.5)$ \\
\hline $\mathrm{UGT1A1}^{*} 60 \mathrm{G}+\mathrm{UGT1A1}^{*}(\mathrm{TA}) 6$ & 86 & 46.3 & $(39.3,53.7)$ \\
\hline $\mathrm{UGT1A1}^{*} 60 \mathrm{~T}+\mathrm{UGT1A1}^{*}(\mathrm{TA}) 7$ & 18 & 9.5 & $(5.4,14.0)$ \\
\hline $\mathrm{UGT1A1}^{*} 60 \mathrm{~T}+\mathrm{UGT1A1}^{*}(\mathrm{TA}) 6$ & 51 & 28.0 & $(21.1,34.0)$ \\
\hline
\end{tabular}

Table V. Frequencies of UGT1A1 polymorphisms in various populations

\begin{tabular}{|c|c|c|c|c|c|c|c|}
\hline Variable & UGT1A1*6 & UGT1A1*27 & UGT1A1*28 & UGT1A1*36 & UGT1A1*37 & UGT1A1 $^{*} 60$ & References \\
\hline \multicolumn{8}{|l|}{ Caucasians } \\
\hline Europeans & $N D^{a}(50)$ & & $0.387(71)$ & ND (71) & ND (71) & $0.351(57)$ & $\begin{array}{c}{[5,16-18} \\
27,28]\end{array}$ \\
\hline Americans & 0.007 (150) & ND (150) & $0.388(147)$ & 0.017 (147) & 0.007 (147) & $0.550(150)$ & \\
\hline Sardinians & & & $0.257(70)$ & ND (70) & ND (70) & & \\
\hline Brazilians & & & $0.324(71)$ & $0.007(71)$ & $0.007(71)$ & & \\
\hline \multicolumn{8}{|l|}{ Africans } \\
\hline Americans & ND (150) & ND (149) & $0.380(200)$ & $0.080(200)$ & $0.020(200)$ & $0.847(150)$ & $\begin{array}{l}{[5,15,16} \\
18,28,29]\end{array}$ \\
\hline Brazilians & & & $0.407(54)$ & $0.065(54)$ & $0.009(54)$ & & \\
\hline Kenyans & & & $0.444(80)$ & $0.100(80)$ & $0.013(80)$ & & \\
\hline \multicolumn{8}{|l|}{ Asians } \\
\hline Japanese & $0.153(301)$ & 0.003 (149) & $0.130(301)$ & ND (301) & ND (301) & $0.262(301)$ & $\begin{array}{c}{[13,18,24,} \\
25,30]\end{array}$ \\
\hline Koreans & $0.213(324)$ & & $0.127(324)$ & ND (324) & ND (324) & $0.267(324)$ & \\
\hline Chinese & $0.230(50)$ & & $0.160(89)$ & ND (89) & ND (89) & $0.300(50)$ & \\
\hline Indians & $0.032(94)$ & & 0.408 (119) & ND (119) & ND (119) & $0.871(176)$ & \\
\hline \multicolumn{8}{|c|}{ Middle-Easterners } \\
\hline Yemenite & & & $0.254(61)$ & ND (61) & ND (61) & & {$[14,15]$} \\
\hline Lebanese & & & $0.357(42)$ & ND (42) & ND (42) & & \\
\hline Egyptians & & & $0.260(50)$ & & & & \\
\hline Saudisb & ND (184) & ND (182) & 0.257 (191) & ND (191) & 0.005 (191) & $0.624(191)$ & \\
\hline
\end{tabular}

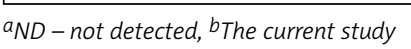

region carries the $(\mathrm{TA}) 8$ repeats variant (i.e., UGT1A1*37); the $(\mathrm{TA}) 5$ repeats variant (i.e., UGT1A1*36) was not present in the studied population. Table IV represents UGT1A1 haplotypes identified in our study. UGT1A $1 * 60$ allele was found to be in a combination with UGT1A1*28 allele in about $16.2 \%$ of subjects, while with UGT1A1 (TA)6 allele in $46.3 \%(95 \% \mathrm{Cl}$ : 39.3, 53.7). The linkage disequilibrium $D^{\prime}$ between UGT1A ${ }^{*} 60$ and UGT1A1* 28 was estimated to be 0.003 with a correlation coefficient $\left(R^{2}\right)$ of 0.005 $(p=0.95)$, concluding no association between the two loci from the studied population.

\section{Discussion}

To our knowledge, the current study is the first to indicate the distribution of some UGT1A1 in Saudi Arabians. The frequency of $U G T 1 A 1^{*} 60$ in the studied population is less than African Americans and Asian Indians but more than that of Chinese and Japanese. On the other hand, UGT1A1*28 prevalence in Saudis is comparable to Egyptians and Yemenites, whereas it is 2-fold higher than Koreans $[12,14]$. Similar to other populations, UGT1A1*37 is a rare mutation [16-18]. The frequencies of these repeat polymorphisms in various populations are given in Table $\mathrm{V}$.

In vitro and in vivo studies showed that increasing the TA repeat number leads to a decrease in the transcriptional activity of UGT1A1. Given the transcriptional activity of $n=6$ defined as $100 \%$, those of $n=5,7$, and 8 were approximately $130 \%, 65 \%$ and $50 \%$, respectively [5]. Patients who are homozygous for the UGT1A1*28 allele may develop severe, dose-limiting toxicity (diarrhea, neutropenia) dur- 
ing irinotecan therapy [19] and a mild type of inherited Gilbert's syndrome [6, 20]. Therefore, a dosing scheme based on the presence of a UGT1A $1^{*} 28$ genotype is currently recommended [21].

Another $1 \mathrm{~A} 1$ polymorphism $211 \mathrm{G}>\mathrm{A}$ (G71R, *6 allele) in exon 1 is also a causative factor for Gilbert's syndrome [22], reduced metabolic activity to $\mathrm{SN}-38$ [23], and lower tumor response and higher incidence of grade 4 neutropenia in Koreans [24]. In the current study, we did not detect UGT1A1*6 polymorphism in Saudis. In addition, $1 \mathrm{~A} 1^{*} 60$ allele $(-3279 \mathrm{~T}>\mathrm{G})$ is located in the distal enhancer region, a phenobarbital-responsive enhancer module, and shows reduced transcriptional activity [7]. This polymorphism was found to be about 2-3-fold more prevalent among studied Saudis compared to Oriental Asians [25]. The combination of UGT1A1*60 allele and UGT1A1*28 allele in about $16.2 \%$ of Saudis may represent a risk of reduced enzyme activity, despite the low D' value. Therefore, the clinical implication of such variants in relation to irinotecan therapy should be further explored in Saudi patients. A minor allele, UGT1A1*27, which has been reported to be associated with Gilbert's syndrome and possibly grade 4 neutropenia with irinotecan-based chemotherapy in Asians $[22,26]$, was not detected in the current study. One limitation of the current study is the lack of gender effect as all screened subjects were males. This however is expected have a minimal consequence for the findings as no sexual dimorphism was previously reported for the human UGT1A1 locus.

In conclusion, the frequencies of important UGT1A1 variants (i.e., UGT1A1*6, UGT1A1*27, UGT1A1*28, $U G T 1 A 1^{\star} 36, U G T 1 A 1^{\star} 37$, and UGT1A1*60) were determined in Saudi Arabians. Both UGT1A1*60 and ${ }^{*} 28$ prevalence is less than in those of African origin but higher than those of Oriental descent. Other studied mutations were either not present or rarely detected. Further studies are needed to investigate the phenotypic patterns of UGT1A1 genotypes in the Arab population.

\section{Acknowledgments}

This study was supported by the National Plan for Science and Technology Program (NPST), King Saud University (Grant08-MED565-02), King Abdulaziz City for Science and Technology, Riyadh, Saudi Arabia.

\section{References}

1. Meech R, Mackenzie PI. Structure and function of uridine diphosphate glucuronosyltransferases. Clin Exp Pharmacol Physiol 1997; 24: 907-15.

2. lyer L, King CD, Whitington PF, et al. Genetic predisposition to the metabolism of irinotecan (CPT-11). Role of uridine diphosphate glucuronosyltransferase isoform 1A1 in the glucuronidation of its active metabolite $(\mathrm{SN}-38)$ in human liver microsomes. J Clin Invest 1998; 101: 847-54.

3. Senafi SB, Clarke DJ, Burchell B. Investigation of the substrate specificity of a cloned expressed human bilirubin UDP-glucuronosyltransferase: UDP-sugar specificity and involvement in steroid and xenobiotic glucuronidation. Biochem J 1994; 303: 233-40.

4. Tukey RH, Strassburg CP. Human UDP-glucuronosyltransferases: metabolism, expression, and disease. Annu Rev Pharmacol Toxicol 2000; 40: 581-616.

5. Beutler E, Gelbart T, Demina A. Racial variability in the UDP-glucuronosyltransferase 1 (UGT1A1) promoter: a balanced polymorphism for regulation of bilirubin metabolism? Proc Natl Acad Sci U S A 1998; 95: 8170-4.

6. Monaghan G, Ryan M, Seddon R, Hume R, Burchell B. Genetic variation in bilirubin UPD-glucuronosyltransferase gene promoter and Gilbert's syndrome. Lancet 1996; 347: 578-81.

7. Sugatani J, Yamakawa K, Yoshinari K, et al. Identification of a defect in the UGT1A1 gene promoter and its association with hyperbilirubinemia. Biochem Biophys Res Commun 2002; 292: $492-7$.

8. Aono S, Yamada Y, Keino H, et al. Identification of defect in the genes for bilirubin UDP-glucuronosyl-transferase in a patient with Crigler-Najjar syndrome type II. Biochem Biophys Res Commun 1993; 197: 1239-44.

9. Udomuksorn W, Elliot DJ, Lewis BC, Mackenzie PI, Yoovathaworn K, Miners JO. Influence of mutations associated with Gilbert and Crigler-Najjar type II syndromes on the glucuronidation kinetics of bilirubin and other UDP-glucuronosyltransferase 1A substrates. Pharmacogenet Genomics 2007; 17: 1017-29.

10. Akaba K, Kimura T, Sasaki A, et al. Neonatal hyperbilirubinemia and mutation of the bilirubin uridine diphosphate-glucuronosyltransferase gene: a common missense mutation among Japanese, Koreans and Chinese. Biochem Mol Biol Int 1998; 46: 21-6.

11. Huang CS, Luo GA, Huang ML, Yu SC, Yang SS. Variations of the bilirubin uridine-diphosphoglucuronosyl transferase $1 \mathrm{~A} 1$ gene in healthy Taiwanese. Pharmacogenetics 2000; 10: 539-44.

12. Bae JW, Choi Cl, Lee JH, Jang CG, Chung MW, Lee SY. Effects of UDP-glucuronosyltransferase polymorphisms on the pharmacokinetics of ezetimibe in healthy subjects. Eur J Clin Pharmacol 2011; 67: 39-45.

13. Saeki M, Saito $Y$, Jinno $H$, et al. Haplotype structures of the UGT1A gene complex in a Japanese population. Pharmacogenomics J 2006; 6: 63-75.

14. Kohle C, Mohrle B, Munzel PA, et al. Frequent co-occurrence of the TATA box mutation associated with Gilbert's syndrome (UGT1A1*28) with other polymorphisms of the UDP-glucuronosyltransferase-1 locus (UGT1A6*2 and

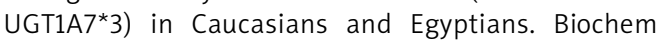
Pharmacol 2003; 65: 1521-7.

15. Premawardhena A, Fisher CA, Liu YT, et al. The global distribution of length polymorphisms of the promoters of the glucuronosyltransferase 1 gene (UGT1A1): hematologic and evolutionary implications. Blood Cells Mol Dis 2003; 31: 98-101.

16. Innocenti F, Grimsley C, Das S, et al. Haplotype structure of the UDP-glucuronosyltransferase 1A1 promoter in different ethnic groups. Pharmacogenetics 2002; 12: 725-33.

17. Innocenti F, Liu W, Chen P, Desai AA, Das S, Ratain MJ. Haplotypes of variants in the UDP-glucuronosyltransferase1A9 and 1A1 genes. Pharmacogenet Genomics 2005; 15: 295-301. 
18. Kaniwa $\mathrm{N}$, Kurose $\mathrm{K}$, Jinno $\mathrm{H}$, et al. Racial variability in haplotype frequencies of UGT1A1 and glucuronidation activity of a novel single nucleotide polymorphism 686C> $\mathrm{T}$ (P229L) found in an African-American. Drug Metab Dispos 2005; 33: 458-65.

19. Ando Y, Saka H, Ando M, et al. Polymorphisms of UDPglucuronosyltransferase gene and irinotecan toxicity: a pharmacogenetic analysis. Cancer Res 2000; 60: 6921-6.

20. Bosma PJ, Chowdhury JR, Bakker C, et al. The genetic basis of the reduced expression of bilirubin UDPglucuronosyltransferase 1 in Gilbert's syndrome. N Engl J Med 1995; 333: 1171-5.

21. Hu ZY, Yu Q, Pei Q, Guo C. Dose-dependent association between $U G T 1 A 1^{*} 28$ genotype and irinotecan-induced neutropenia: low doses also increase risk. Clin Cancer Res 2010; 16: 3832-42.

22. Aono S, Adachi Y, Uyama E, et al. Analysis of genes for bilirubin UDP-glucuronosyltransferase in Gilbert's syndrome. Lancet 1995; 345: 958-9.

23. Jinno H, Tanaka-Kagawa T, Hanioka N, et al. Glucuronidation of 7-ethyl-10-hydroxycamptothecin (SN-38), an active metabolite of irinotecan (CPT-11), by human UGT1A1 variants, G71R, P229Q, and Y486D. Drug Metab Dispos 2003; 31: 108-13.

24. Han JY, Lim HS, Shin ES, et al. Comprehensive analysis of UGT1A polymorphisms predictive for pharmacokinetics and treatment outcome in patients with non-small-cell lung cancer treated with irinotecan and cisplatin. J Clin Oncol 2006; 24: 2237-44.

25. Ki CS, Lee KA, Lee SY, et al. Haplotype structure of the UDP-glucuronosyltransferase 1A1 (UGT1A1) gene and its relationship to serum total bilirubin concentration in a male Korean population. Clin Chem 2003; 49: 2078-81.

26. Nakamura Y, Soda H, Oka M, et al. Randomized phase II trial of irinotecan with paclitaxel or gemcitabine for nonsmall cell lung cancer: association of UGT1A1* 6 and UGT1A1*27 with severe neutropenia. J Thorac Oncol 2010; 6: 121-7.

27. Hall D, Ybazeta G, Destro-Bisol G, Petzl-Erler ML, Di Rienzo A. Variability at the uridine diphosphate glucuro nosyltransferase 1A1 promoter in human populations and primates. Pharmacogenetics 1999; 9: 591-9.

28. Fertrin KY, Goncalves MS, Saad ST, Costa FF. Frequencies of UDP-glucuronosyltransferase 1 (UGT1A1) gene promoter polymorphisms among distinct ethnic groups from Brazil. Am J Med Genet 2002; 108: 117-9.

29. Guillemette C, Millikan RC, Newman B, Housman DE. Genetic polymorphisms in uridine diphospho-glucuronosyltransferase $1 \mathrm{~A} 1$ and association with breast cancer among African Americans. Cancer Res 2000; 60: 950-6.

30. Balram C, Sabapathy K, Fei G, Khoo KS, Lee EJ. Genetic polymorphisms of UDP-glucuronosyltransferase in Asians: UGT1A ${ }^{\star} 28$ is a common allele in Indians. Pharmacogenetics 2002; 12: 81-3. 